\title{
Challenges for on-Demand Technology and the Unseen Opportunities
}

\author{
Shaharia Arafat, MBA \\ Fontbonne University, USA \\ Business Analyst, CollaboraIT Inc. USA \\ Co-founder, Tech Cardinals LLC, USA
}

\begin{abstract}
The pursuit of immediate services and goods have underlied the rapid development of on-demand technology. Ondemand technology offers less interaction than conventional methods. It has disrupted the conventional way of obtaining goods or services by offering a way to get immediate goods and services in real time and even on the go. The rising of on-demand technology and startups has led to the creation of an on-demand economy where conventional services are repacked in new modes of delivery and accommodate a wide range of users. More than 30 articles and journals are cited in this paper to provide a thorough discussion about on-demand technology, including the current challenges and future development of on-demand technology. This paper discusses ondemand technology along with how on-demand technology can disrupt the conventional method of obtaining services and goods. There are five unseen opportunities that new and current companies can leverage to create an on-demand economy. Those are real time technology, background history and capability, interactive maps, pricing, and distance-wise priority.
\end{abstract}

Keywords: On-demand technology, on-demand economy, service network, disruptive innovation, idea and opportunity for new startups

\section{Introduction}

In the present state, businesses operating in the on-demand economy are an extension of conventional services repacked in new modes of delivery and accommodating a wide range of users (Chesbrough, 2013; Juggernaut, 2016). The phrase On-Demand refers to the economic opportunity and activities developed by technology-driven companies to fulfill consumer demand via the immediate supply of goods and services (Patel, 2016). The supply side of on-demand technologies is programmed via an intuitive and efficient digital layer existing on top of infrastructure networks. Such methods are not only efficient but revolutionary, as they provide fast and effective solutions to everyday problems. Start-ups using the on-demand business model have made fortunes overnight using on-demand technology. However, there are a sufficient number of problems and unidentified opportunities that are waiting to be exploited (Burson-Marsteller, 2016; Giri \& Singh, 2014). Despite the success of on-demand technologies, some constant security challenges inherent to mobile-based technologies have been identified. The issues raised in many international circles over on-demand mobile services adoption is the safety and security of users, and the safety of the service provider and underlying infrastructure (Lewis \& Wyatt, 2014). Security issues related to network technologies such as Global System for Mobile Communication (GSM), quality of communication, or connectivity infrastructure, and other issues related to wireless devices such as user interface, information disclosure, speed, privacy, and pricing have been identified (Juggernaut, 2016). It is important for companies to critically review their business models and address concerns related to user privacy and security by providing users with the ability to control their visibility in public domains.

The on-demand economy has created major disruptions in past years by studying consumer behavior and supplying goods and services at the right place at the right time (Pavlou, 2003). According to a survey of ondemand consumer adoption in the United States, $42 \%$ of the population in the country has used on-demand services and $51 \%$ of the population has offered on-demand services, leading to improvements in their financial situation (Burson-Marsteller, 2016). Essential learning from business leaders in on-demand technology dictates three key reasons for business success (Giri \& Singh, 2014). First, focus on improving predictions about fulfilling-demand in real time. Customers have limited time to look for daily-need services. Businesses must reinvent their business model to capture consumers through innovative and time-saving methods. Second, simplicity has become the key driver of revenue. 
Safeguarding consumers from complex backend technology with a simple intuitive user experience is a proven strategy for successful business. Third, start-ups such as Uber and AirBnB experienced losses up to \$1 million, but the leadership continued to push forward its vision and goals, leading to business success (Curley \& Slocum, 2016). Addressing problems swiftly and adapting to changing environments has become the key to business success.

This paper provides a comprehensive discussion about the On-demand startup, its future potential, the issues of "on-demand" technology, the unseen opportunities to create "on-demand" economy, and current and future "ondemand" startup sectors. More than 30 articles and journals are cited and reviewed to give a comprehensive look at the "on-demand" startup. A review of these papers will give the reader a complete overview of the current development of "on-demand" startup, technology, economy, and its future.

\section{THEORETICAL IMPLICATIONS}

\section{II.1 ON-DEMAND TECHNOLOGY}

On-Demand Technology is defined as the technology that fulfills consumer needsvia the immediate provisioning of goods and services (Forbes, 2014). On-demand service, in the context of IT, is a prime facility and feature of cloud computing services, which allow users to provision raw cloud resources at run time, when and where needed. On-demand service allows end users to use cloud computing, storage, software, and other resources instantly and in many cases without limits. This addition of resources is generally performed in live environments through a transition process that doesn't affect current operations. On-demand technology allows consumers and producers to interact or do a transaction without requiring human interaction between both parties. This technology allows consumers to get prompt or even immediate delivery of services or goods. Over the last few years, our society has transformed into a society that wants everything on-demand, ranging from TV series, and thmovies we watch, to the radio programs and music we listen to. In 2004, Accela Communications conducted a research study about registrants who view rich media content by format. Accela Communications analyzed nearly 12,000 webcast registrants across multiple rich media programs. Only $28 \%$ of individuals who pre-registered for a live presentation came back to attend the program at the scheduled time, despite receiving multiple reminder notices. However, among those that who registered when the program was available on-demand, $91 \%$ viewed the content (Wainhouse Research, 2004). Figure 1 below shows a graph illustrating how providing on-demand content yields greater viewing results.

\section{Registrants Who View Rich Media Content by Format}

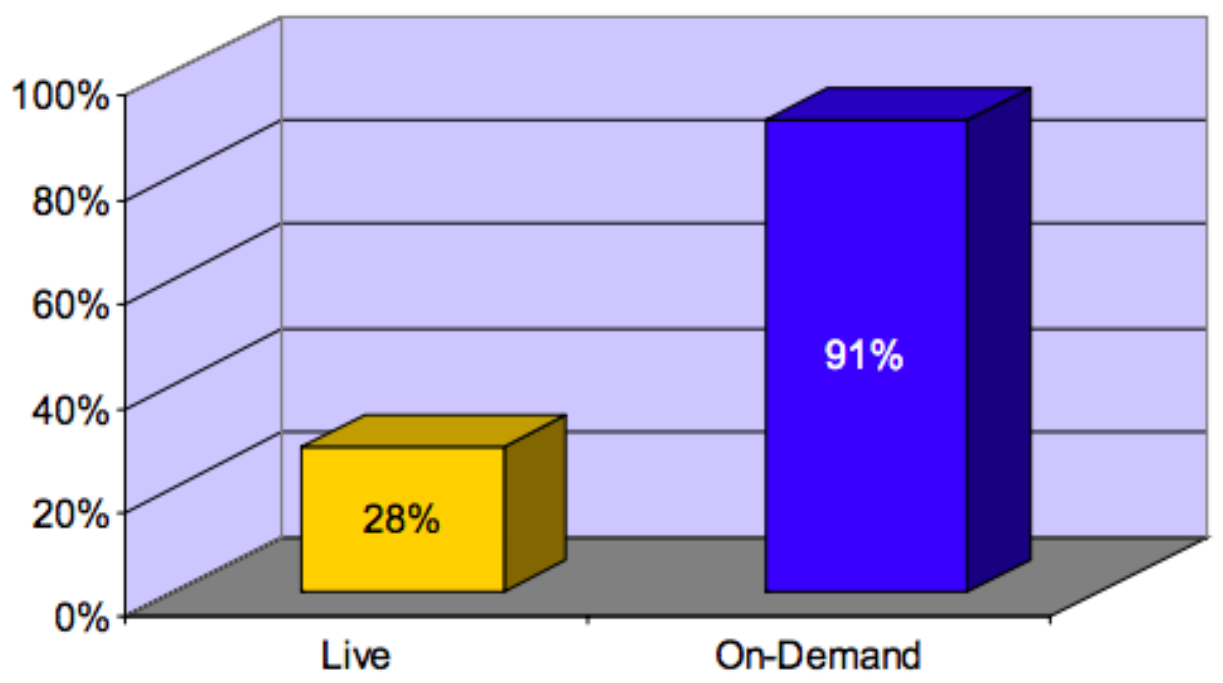

Figure 1. On-demand content yields greater viewing results (Wainhouse Research, 2004). 


\section{II.2 THE RISING OF ON-DEMAND TECHNOLOGY START-UPS}

In 2004, Wainhouse Research conducted on-demand market research. Particularly, they forecasted the future market for on-demand rich media. by looking at similar technologies being used for similar applications and sold in a comparable manner. The web conferencing market has seen annual growth rates of $35 \%$ to $50 \%$ in periods from 2000 to 2003, and Wain house Research forecasts the compound annual growth rate from 2004 to 2007 to be 16\% (Wainhouse Research, 2004). Figure 2 below shows the market forecast chart of on-demand rich media market from 2003 to 2007 that was conducted by Wainhouse Research.

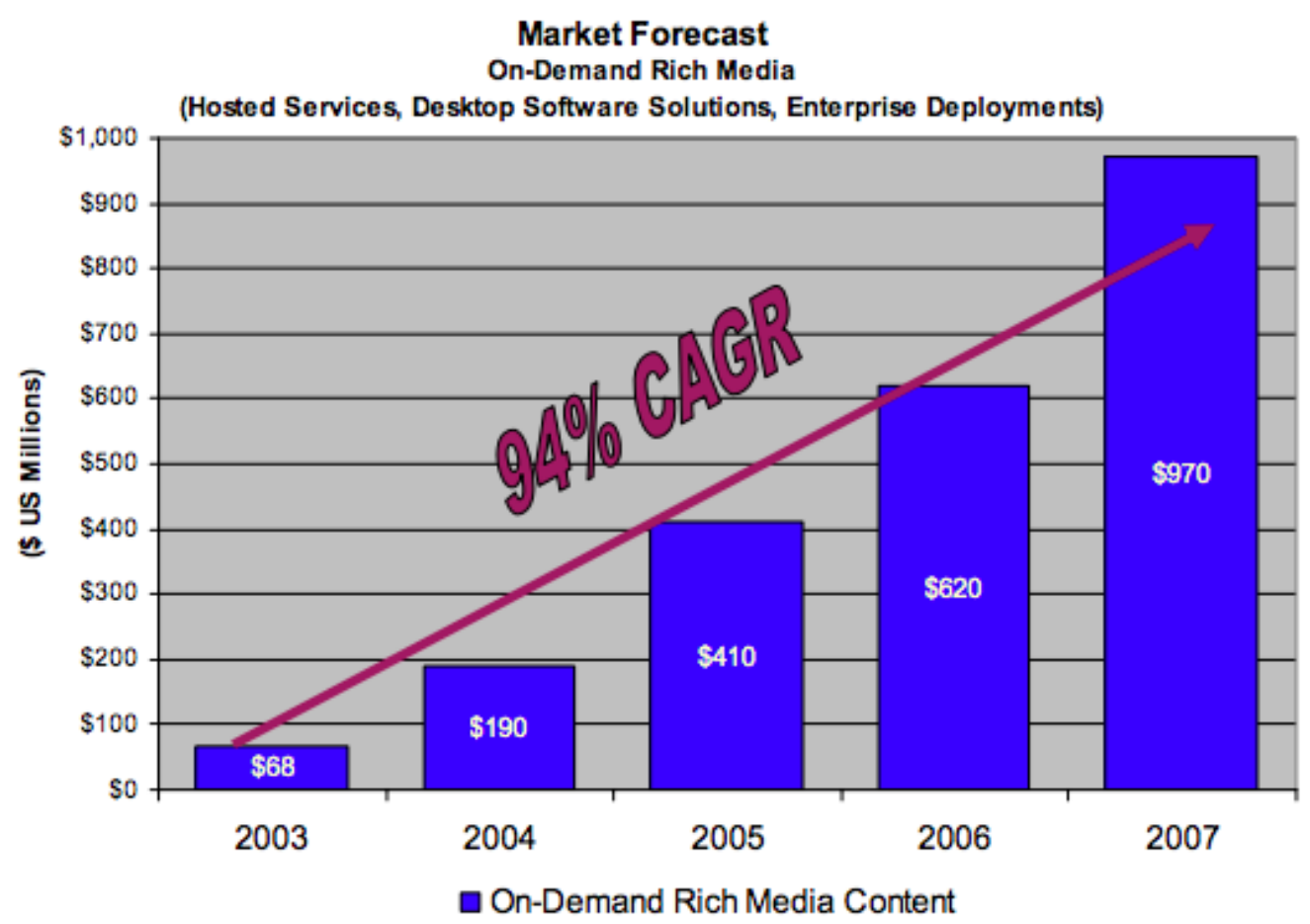

Figure 2. On-demand rich media content market forecast chart (Wainhouse Research, 2004).

For comparison, in 2015, FMI analysis found that the global video on-demand market was valued at 45 billion U.S. dollars in 2014. This market was expected to expand at a cumulative annual growth rate (CAGR) of $8.3 \%$ during the period 2016 - 2026. During that period, the region that will contribute the highest growth is the market in the Asian Pacific region (excluding Japan). This is because the growth of high speed Internet services in Asia Pacific region will create a future potential of users of video on-demand services such as Netflix, Home Box Office Inc (HBO), and Hulu. The rising number of smartphone users and penetration of the market also will potentially support the growth of video on-demand services users (FMI Analysis, 2015). Figure 3 below illustrates the forecast of global video on-demand (VoD) market value.

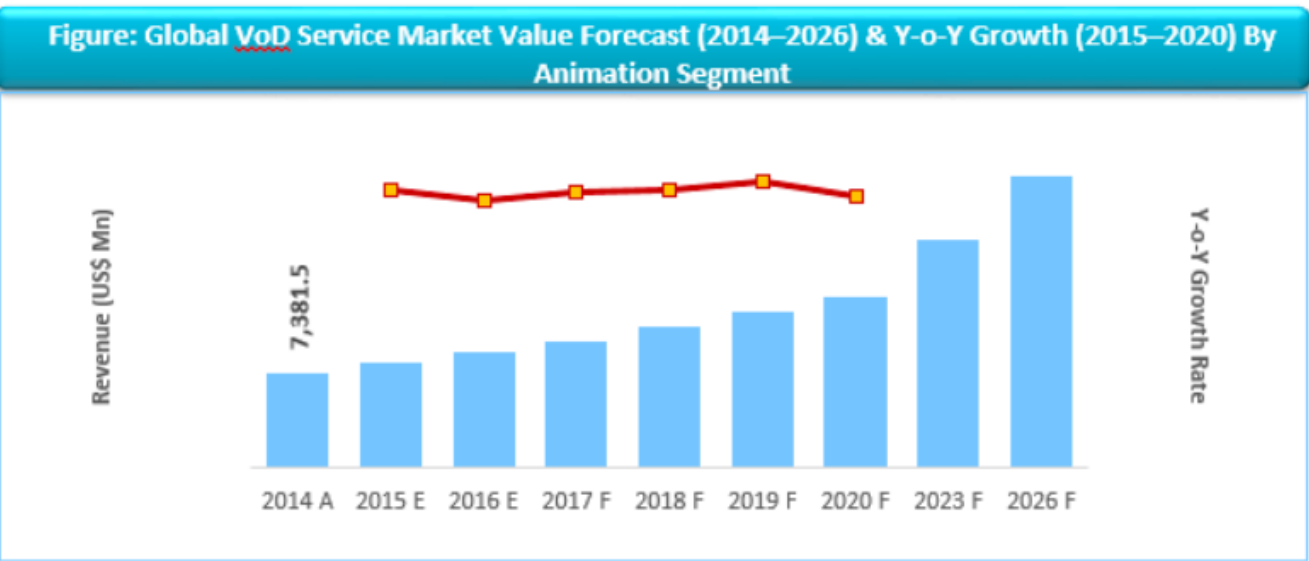

Figure 3. Global VoD Service Market Value Forecast (2014 - 2026) (FMI Analysis, 2015). 
Due to its rising potential, the startups that offer on-demand technology hasrisen up in the past years. From the success of Facebook, Google, Amazon, Uber, AirBnB, and many others, the core learning to adopt is to have the right vision and ambition (Salamzadeh \& Kawamorita, 2015). Start-ups have been making successful strides in areas of food delivery services (e.g., Deliveroo, Blue Apron, Hello Fresh, and Plated), banking services for kids (e.g., Osper, Pennybox, and Piggy) and financial services (e.g., Due, Betterment and True Accord, and TransferWise) (Salamzadeh \& Kawamorita, 2015). There are many opportunities for start-ups to enter the market either in a recognized industry or a completely new service built on a mobile delivery platform. Start-ups such as Ola, GrabTaxi, and LeCab in the travel industry have significant competition from more established players such as Uber, Lyft, and Hailo. A survey of recent trends in the start-up industry reveals corporate wellness programs, social network game development, Internet publishing, and e-commerce online auctions as the most promising sectors in 2017 (Forbes, 2016).

\section{Practical Implications}

\section{III.1 ChallengeS FOR START-UPS BASEd IN ON-DEMAND TECHNOLOGY}

Despite its potential growth, there are many challenges on the development of on-demand technology. From our findings, we determined that there are two main challenges on the development of on-demand technology. Those are security challenges, and legal challenges.

\section{Security Challenges}

The business framework is a combination of on-demand services such as logistics, vendor management and interfacing, and consumer technologies (Phillips \& McKeown, 2016). In a survey by CITO (2015), mobile application security was cited as the top challenge. The key issues highlighted in mobile security are use of multiple devices, ad-surfing, using mobile devices in unsecured networks, theft, and using unsecured applications. According to Bailis et al. (2016), as long as the security measures are proactive, businesses in the on-demand economy are ahead of security threats. The majority of mobile apps are certified, but it is found that many advertisements in certified apps generate traffic towards uncertified apps and unsecured networks. As these apps and services are not traceable on official app stores, they can potentially damage consumer experiences and pose a serious threat to advertisers. A three-dimensional approach has been advanced by Lord (2014) which suggeststhat combining networks, devices, and applications in a single secure layer will improve security and resolve such issues. Security challenges are cited as the common reason for reluctance in the adoption of mobile technologies (Tarhini et al., 2016).

\section{Legal Challenges}

The increasing number of legal hurdles for innovative technology companies is in the field of information privacy protection (Bailis et al., 2016). There is no evidence of legal obligations on behalf of the service provider to collect, store, or transmit personal information. Scholars have not reached a consensus in legal statutes on a uniform definition of information privacy (Sharafizad \& Coetzer, 2016). While some businesses claim to own user information as a part of their contract with the user of a mobile service, other businesses claim no ownership over user data. In recent years, the federal government and international legal bodies have expressed rising concerns over customer information privacy and directed start-ups to take privacy issues into consideration. Similarly, businesses in the on-demand economy will be enforced to maintain and implement security programs to address privacy concern (Bocken \& Short, 2016). Companies that fail to provide privacy and security to users of mobile technologies will be charged with deceptive trade practices. The concerns put forth by government institutions about improving the safety and privacy of information passed over the Internet will help new and emerging companies to provide a secured safety net for protecting user information.

\section{Potential Opportunities of Future On-Demand Services}

The present global population seeks Internet-based search engines for their daily needs. The Internet has multiple service providers selling value-added services without credibility, cost-transparency, and location information, making it difficult for users to make a decision. Websites offering products and services often function in the form of classified ads. While there is no credible feedback on those service providers, costing structures, or location information, there is a scope for mobile on-demand service providers to consolidate these loopholes and innovate such service provisioning applications. Companies offering a credible service provider database with real-time information about their service areas, costs, and feedback will prevent users from venturing towards unsafe service providers. 
Research suggests that the rise of mobile application environments will increase consumer adoption and trust towards innovative services (Lee \& Raghu, 2014; Zadok \& Puustinen, 2010). One of the key challenges for ondemand service providers would be to prevent fraudulent service providers from posting advertisements or altering their feedback from users.

At present, there are on-demand technologies such as UBER and house rental companies such asAirBnB offering valuable services to the mobile consumer. Similarly, there are classified advertising economies such as Craigslist and Backpage, among others, that provide service ads for multiple types of services. There have been disparate efforts in bringing both the concepts together, i.e., On-Demand technology and business model benefits in classified advertising. This study identifies five unseen opportunities that new and current companies can leverage to create an on-demand economy.

\section{a) Real Time Technology}

There is a lack of real-time, location-based, person-to-person exchange of goods and services. Mobile companies have yet to turn traditional classified listings into Twitter-sized micro listings (Feldman, 2014). Perhaps an app could quickly connect with people nearby and allow users to search for items or services. These apps would connect users with geo-tagged maps that show up once a user clicks on it and connects them instantaneously (Gabrielli et al., 2013). Transactions could be started over a text message or phone calls and connect the users with the service provider through a Google Maps route. Real-time technology could allow fast-paced advertising and geo-located classified ads. On-demand mobile applications will have to use the ideas on which sites like Craigslist and Backpacker were built and combine them with mobile and GPS technologies.

\section{b) Background History and Credibility}

Classified advertising is a great resource for users, as it provides listings for a wide range of legitimate opportunities (Lord, 2014). However, there are advertisements that are too good to be true or perhaps an opportunity to con people into taking memberships or depositing advance payments for a service. It is imperative to approach all jobs on classified advertising websites with caution. Checking the dates of job postings is one of the popular ways to know if a position has been filled or whether applying for it is going to be a waste of time. Listings that are left on for too long could mean that the position has been filled but the author failed to delete the listing. Protecting your financial account information is crucial to avoid losses. Service industry needs to improve regulations on classified advertising that seeks personal information from users. On-demand services can leverage from credibility scores and service provider rankings to help connect reputed service providers with regular customers.

\section{c) Interactive Maps}

Modern users tend to use maps and geo-tagging services frequently to access new places and find the best routes to day-to-day locations. The growth of the Internet has made it accessible for a variety of users to use locationbased services. However, they are still emerging, as more and more services providers are tagging them through geo-tagging (Kramers, 2014). This allows users to access service providers in close proximity with navigation options. Interactive maps combined with geo-tagging will improve credibility, ease of access, and visibility of the service providers, making them accessible for people in the local community.

\section{d) Pricing}

A great advantage for users would be to compare prices of services when seeking classified ad listings. Traditionally, a service provider posts an ad online in a classified website which is viewed by millions of users. Classified ads often stay live for a long period which affects the ability of the service provider to moderate its pricing information. Cost is a major detrimental factor when it comes to shortlisting service providers and companies offering user-targeted solutions. Therefore, there is a tremendous potential of growth and healthy competition when pricing information is available from service providers. Alternatively, new businesses can create service guidelines with mandatory cost and pricing information. Businesses will have to update their pricing information regularly and stick to it if a user chooses to use these services.

\section{e) Distance-wise Priority}

Mobile apps provide accurate distance information of service providers that helps in improving customer feedback and experience (Koufaris, 2002). Users have reported that they value services offered in close proximity over cost and overall ratings of the service provider. 
Classified ad listings can benefit from distance-wise priority rankings for service providers in a mobile app based environment. Users can log into their devices and the mobile technology would access their location and provide them with best possible options in the nearest location. Users have reported that obtaining services from businesses that are located in the community helps social interactions and word-of-mouth publicity. Businesses such as Uber and other car rental services make use of distance-wise priority to lower costs. Prioritizing using distance charts can create equal opportunities for all types of businesses.

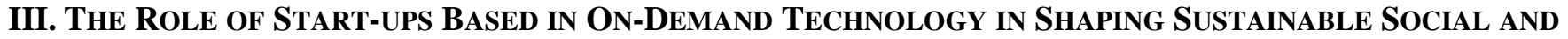 ECONOMIC DEVELOPMENT}

On-demand services using social media and technology platforms will play a vital role in shaping sustainable solutions (Bocken \& Short, 2016). With over 6.2 billion mobile phone subscriptions and likely to reach 9 billion by 2020 , mobile phones are running towards global adoption (Ries, 2011). While urban cities are witnessing a surge in app-based services offering home delivery of almost any item that was conventionally purchased in the market, there is little but promising growth in the rural sector on addressing basic human needs in areas of healthcare, transport, education, and finance. The key to successful social sustainability through better health, community development, and putting peoples' needs before profits rests on top companies in mobile technologies markets. Whether it is disease response, education through gamification, monitoring government accountability, preserving natural resources, or developing adequate disaster response, mobile is the key to social sustainability and development.

The overwhelming success of the mobile app development among consumers has helped in generating greater revenues, but how well does it relate to economic sustainability? Results from Forbes (2016) indicate that the growth of mobile application development among developing countries has more than tripled in the last ten years. The economic sustainability of companies providing revolutionary on-demand services through mobile based apps depends on the quality of software, its scope, and the benefits created for the user. An app may be very useful from the outside, but have bad customer experience feedback. Similarly, a not-so-useful app with a simple intuitive design and easy of browsing experience may generate value for the customer and thus for the company. Therefore, a company must consider these areas to remain profitable and maintain its existing application software while developing and testing new applications.

\section{Future Potential SERVICES IN FUtURe ON-DEMAND TeChNOLOGY STARTUP}

Convenience and cost-saving factors have attracted consumers and end users to use the on-demand services that have been offered by on-demand technology startups such as Uber and Lyft. In 2016, Bloomberg reported that Uber had massive and rapid growth. In the last three months of 2016, gross bookings increased 28 percent from the previous quarter to $\$ 6.9$ billion. The company generated $\$ 2.9$ billion in revenue, a 74 percent increase from the third quarter. Losses rose 6.1 percent over the same period to \$991 million (Bloomberg, 2016). Figure 4 shows the growth of Uber's revenue

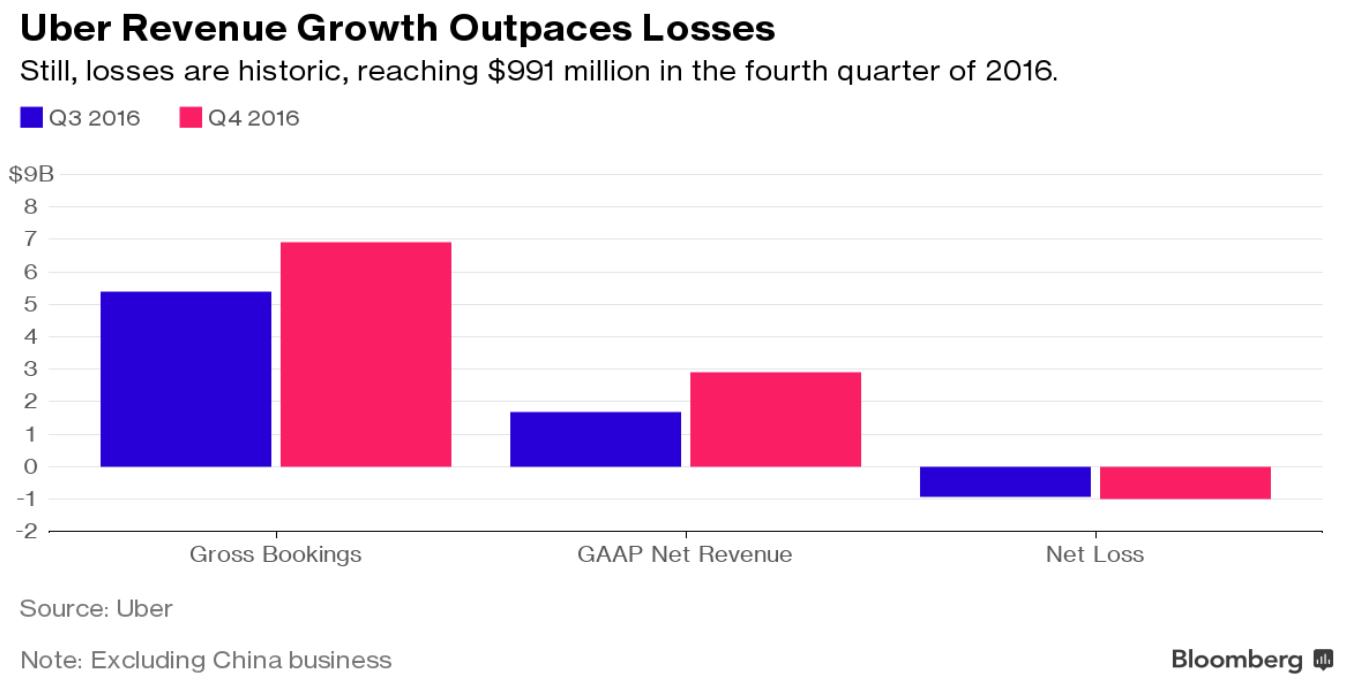

Figure 4. Uber's Revenue Growth in between Q3 and Q4 of 2016 (Bloomberg, 2017). 
The gross bookings or the total values of fares of Uber also have risen up from twobillion dollars in 2013 to over 20 billion dollars in 2016. Figure 5 describes the growth of Uber's gross booking in detail.

\section{Uber's Gross Bookings}

Gross bookings, essentially the total value of fares, grew 126 percent in 2016.

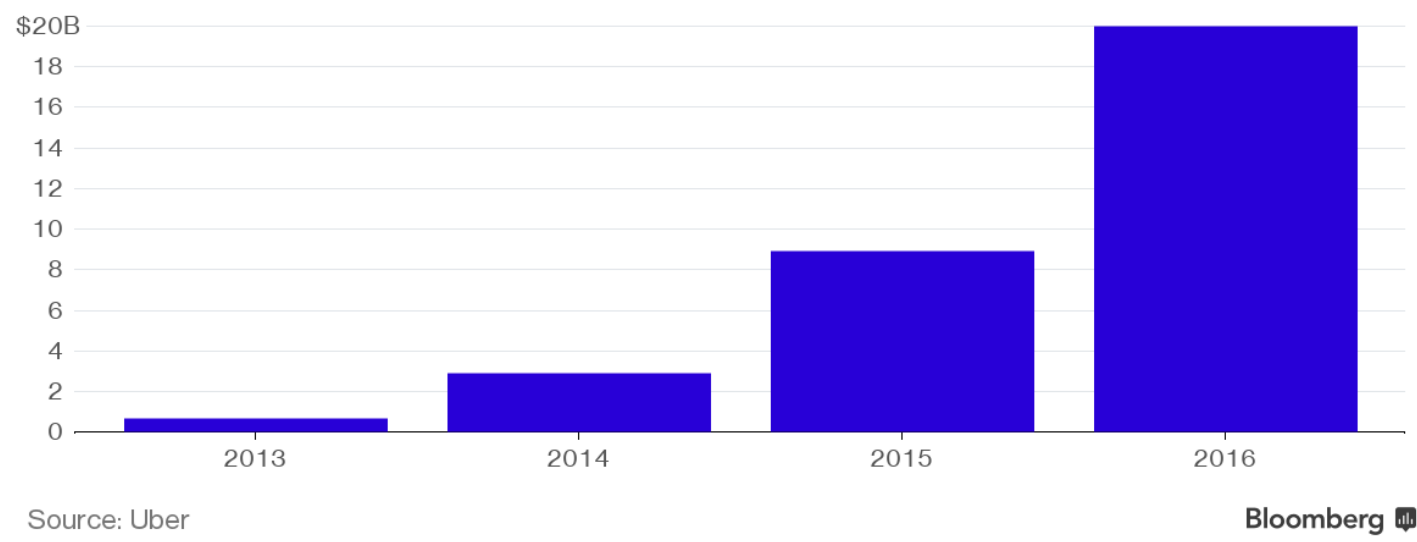

Figure 5. Uber's Gross Bookings Growth from 2013 to 2016 (Bloomberg, 2017).

This growth has attracted venture capitalists to invest in "on-demand" startups in the past few years. Crunchbase report showed that more than $75 \%$ of funding has gone to just five "on-demand" startups. Figure 6 shows the funding statistics from venture capitalists to the "on-demand" startups. This fact also led to the rising of "ondemand" startups in other sectors of transportations and logistics. The emerging "on-demand" startups sectors that also have emerged are travel and tourism, health care, real estate, home services, pet services, child care, beauty, floral, laundry, legal, education, and Internet services (Quartz, 2017). Figure 7 depicts the "on-demand" startups sectors that have been funded by venture capitalists.

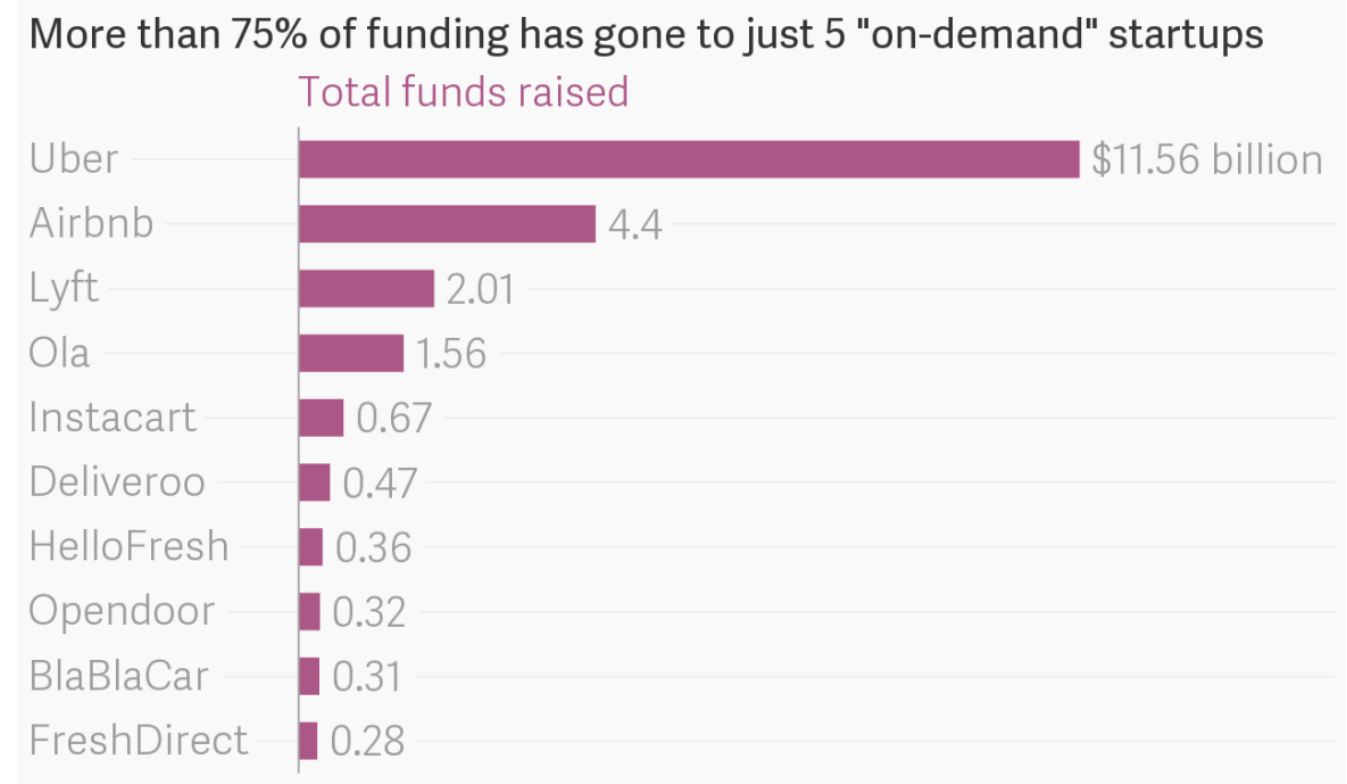

Figure 6. Venture capitalist funding statistics (Quartz, 2017). 


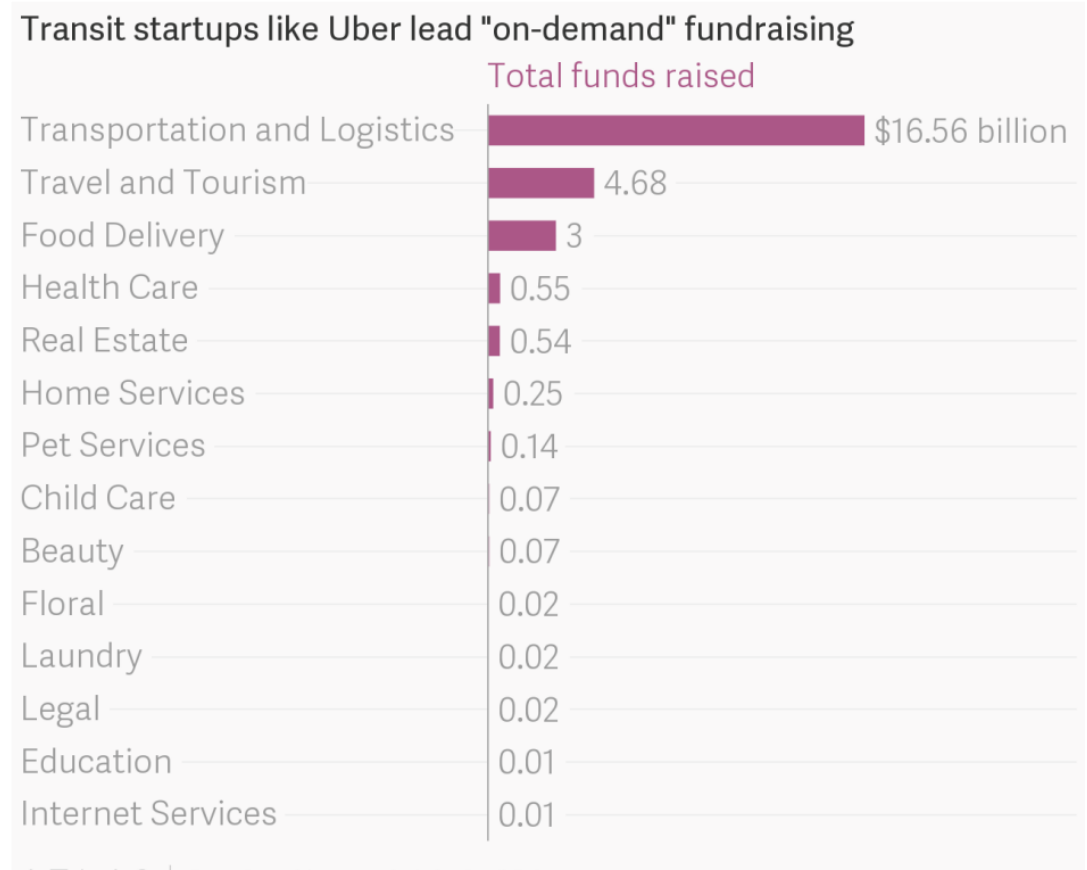

Figure 7. The list of "on-demand" startup sectors that have been funded by venture capitalists (Quartz, 2017).

\section{CONCLUSION}

Convenience and cost-saving has attracted lots of consumers and end users to use the "on-demand" services. This has led to the rapid growth of "on-demand" startups and also the emergence of new "on-demand" startups in various sectors. However, there are two main challenges to the development of "on-demand" startup. Those are legal challenges and security challenges. The rising number of "on-demand" startups also will play a vital role in shaping sustainable solutions. We have reviewed prior researchstudies of "on-demand" startups and their future potential and opportunities in this paper. Based upon that review, it can be concluded that there are five unseen opportunities that new and current companies can leverage to create an on-demand economy. Those are real time technology, background history and capability, interactive maps, pricing, and distance-wise priority. We also found that current and future "on-demand" startups will provide services in over 10 sectors in our society varying from transportation and logistics, travel and tourism, food delivery, health care, real estate, home services, pet services, etc.

\section{References}

Bailis, P., Yang, J., Reddi, V.J. \& Zhu, Y., (2016). Research for practice: web security and mobile web computing. Communications of the ACM, 60(1), 50-53.

Uber, Lifting Financial Veil, Says Sales Growth Outpaces Losses. (2017). Retrieved from https://www.bloomberg.com/news/articles/2017-04-14/embattled-uber-reports-strong-sales-growth-as-lossescontinue.

Bocken, N.M.P. \& Short, S.W., (2016). owards a sufficiency-driven business model: Experiences and opportunities.Environmental Innovation and Societal Transitions, 18, 41-61.

Burson-Marsteller,(2016). Forty-Five Million Americans Say They Have Worked in the On-Demand Economy, While 86.5 Million Have Used It, According to New Survey. Retrieved from http://www.bursonmarsteller.com/press-release/forty-five-million-americans-say-they-have-worked-in-the-on-demand-economywhile-86-5-million-have-used-it-according-to-new-survey/

Chesbrough, H., (2013). Open business models: How to thrive in the new innovation landscape. Harvard Business Press.

CITO, (2015). Executive Enteprise - Mobility Report. Retrieved from http://www.evolvedmedia.com/wpcontent/uploads/2016/03/CITO-Research_Apperian_Executive-Enterprise-Mobility-Report_ResearchReport_2015.pdf. 
Curley, A. \& Slocum, J., (2016). Organizing a Startup Business According to Differentiation Strategy and Virtual Design.

Desmet, L. et al., (2007). A flexible security architecture to support third-party applications on mobile devices. In Proceedings of the 2007 ACM workshop on Computer security architecture (pp. 19-28). ACM.

Feldman, R., (2014). Patent demands \& startup companies: The view from the venture capital community.

Forbes, (2014). The 'On-Demand Economy' Is Revolutionizing Consumer Behaviour - Here's how Retrieved from http://www.businessinsider.com/the-on-demand-economy-2014-7/?IR=T.

Forbes, (2016). 11 Hottest Industries for Startups. Retrieved from https://www.forbes.com/pictures/efgg45kmfg/e-commerce-online-auctions/\#392877cd889b.

FMI Analysis, (2015). Video On-Demand Market Retrieved from: https://www.futuremarketinsights.com/reports/video-on-demand-market.

Gabrielli, S. et al., (2013). Designing motivational features for sustainable urban mobility. In CHI'13 Extended Abstracts on Human Factors in Computing Systems (pp. 1461-1466). ACM.

Giri, M. \& Singh, S., (2014). Issues in Mobile e-commerce: A survey. International Journal of Computer Science and Information Technology, 5(4), pp.5068-70.

Juggernaut, (2016). On Demand Economy | Statistics that Define the Future of On Demand Startups. Retrieved from http://nextjuggernaut.com/blog/on-demand-economy-survey-stats-future-economy-funding-trends-on-demandstartups/.

Koufaris, M., (2002). Applying the technology acceptance model and flow theory to online consumer behavior. Information systems research, 13(2), 205-223.

Kramers, A., (2014). Designing next generation multimodal traveler information systems to support sustainabilityoriented decisions. Environmental Modelling \& Software, 56, 83-93.

Lee, G. \& Raghu, T.S., (2014). Determinants of mobile apps' success: evidence from the App Store market.Journal of Management Information Systems, 31(2), 133-170.

Lewis, T.L. \& Wyatt, J.C., (2014). mHealth and mobile medical apps: a framework to assess risk and promote safer use. Journal of medical Internet research, 16(9), e210.

Lord, N., (2014). Startups \& Data Breaches: How a Startup Can Protect Itself From a Data Breach in 2014 \& Beyond. Retrieved from https://digitalguardian.com/blog/startups-data-breaches-how-startup-can-protect-itself-databreach-2014-beyond.

Mutchler, P. et al., (2015). A large-scale study of mobile web app security. Mobile Security Techologies.

Patel, S., (2016). In defense of the Uber-ization of everything. Retrieved from https://techcrunch.com/2016/06/19/in-defense-of-the-uber-ization-of-everything/.

Pavlou, P.A., (2003). Consumer Acceptance of Electronic Commerce: Integrating Trust and Risk with the Technology Acceptance Model. International Journal of Electronic Commerce.

Phillips, K. \& McKeown, T., (2016). Understanding Self-Employment: The Opportunities and the Challenges for Good Policy. Government, SMEs and Entrepreneurship Development: Policy, Practice and Challenges, 157.

Quartz, (2017). The On-demand economy is a bubble - and it's about to burst. Retrieved from https://qz.com/967474/the-on-demand-economy-is-a-bubble-and-its-about-to-burst/

Ries, E., (2011). The lean startup: How today's entrepreneurs use continuous innovation to create radically successful businesses. Crown Business.

Salamzadeh, A. \& Kawamorita, K.H., (2015). Startup Companies: Life Cycle and Challenges.

Sharafizad, J. \& Coetzer, A., (2016). Women business owners' start-up motivations and network content.Journal of Small Business and Enterprise Development, 23(2), 590-610.

Tarhini, A., Hone, K., Liu, X. \& Tarhini, T., (2016). Examining the moderating effect of individual-level cultural values on users' acceptance of E-learning in developing countries: a structural equation modeling of an extended technology acceptance model. Interactive Learning Environments, 1-23.

Wainhouse Research, (2004). The Business Case for On-Demand Rich Media (ODRM) Retrieved from http://www.wainhouse.com/files/papers/wr-bizcase4odrm.pdf

Zadok, G. \& Puustinen, R., (2010). The Green Switch: Designing for Sustainability in Mobile Computing. In SustainIT.

Zu, H., Xiong, H., Ge, Y. \& Chen, E., (2014). Mobile app recommendations with security and privacy awareness. In Proceedings of the 20th ACM SIGKDD international conference on Knowledge discovery and data mining (pp. 951-960). ACM. 